\title{
8
}
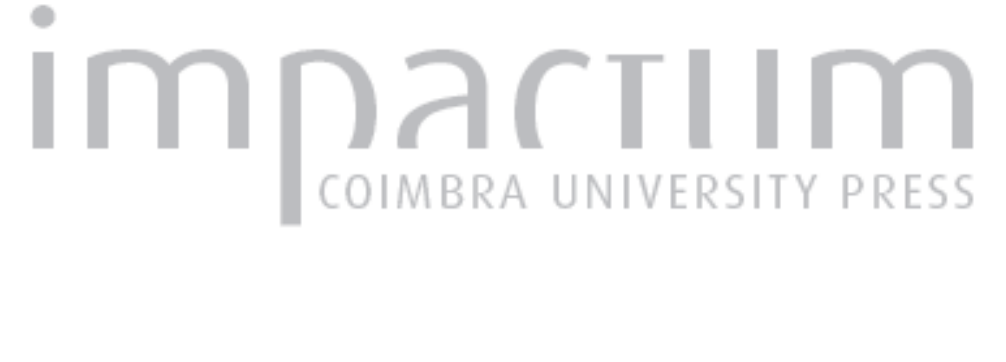

\section{Efeito do incêndio de Catraia no comportamento hidrológico da bacia hidrográfica do} rio Séqua

\author{
Autor(es): $\quad$ Almeida, Soraia; Martins, Fernando; Fernandez, Helena; Pedras, \\ Celestina; Silva, Elisa; Costa, Rui; Lança, Rui \\ Publicado por: Associação Portuguesa de Riscos, Prevenção e Segurança; Imprensa \\ URL \\ persistente: \\ URI:http://hdl.handle.net/10316.2/39757 \\ DOI: DOI:https://doi.org/10.14195/1647-7723_23_12
}

Accessed : $\quad$ 26-Apr-2023 12:57:27

A navegação consulta e descarregamento dos títulos inseridos nas Bibliotecas Digitais UC Digitalis, UC Pombalina e UC Impactum, pressupõem a aceitação plena e sem reservas dos Termos e Condições de Uso destas Bibliotecas Digitais, disponíveis em https://digitalis.uc.pt/pt-pt/termos.

Conforme exposto nos referidos Termos e Condições de Uso, o descarregamento de títulos de acesso restrito requer uma licença válida de autorização devendo o utilizador aceder ao(s) documento(s) a partir de um endereço de IP da instituição detentora da supramencionada licença.

Ao utilizador é apenas permitido o descarregamento para uso pessoal, pelo que o emprego do(s) título(s) descarregado(s) para outro fim, designadamente comercial, carece de autorização do respetivo autor ou editor da obra.

Na medida em que todas as obras da UC Digitalis se encontram protegidas pelo Código do Direito de Autor e Direitos Conexos e demais legislação aplicável, toda a cópia, parcial ou total, deste documento, nos casos em que é legalmente admitida, deverá conter ou fazer-se acompanhar por este aviso.

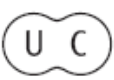




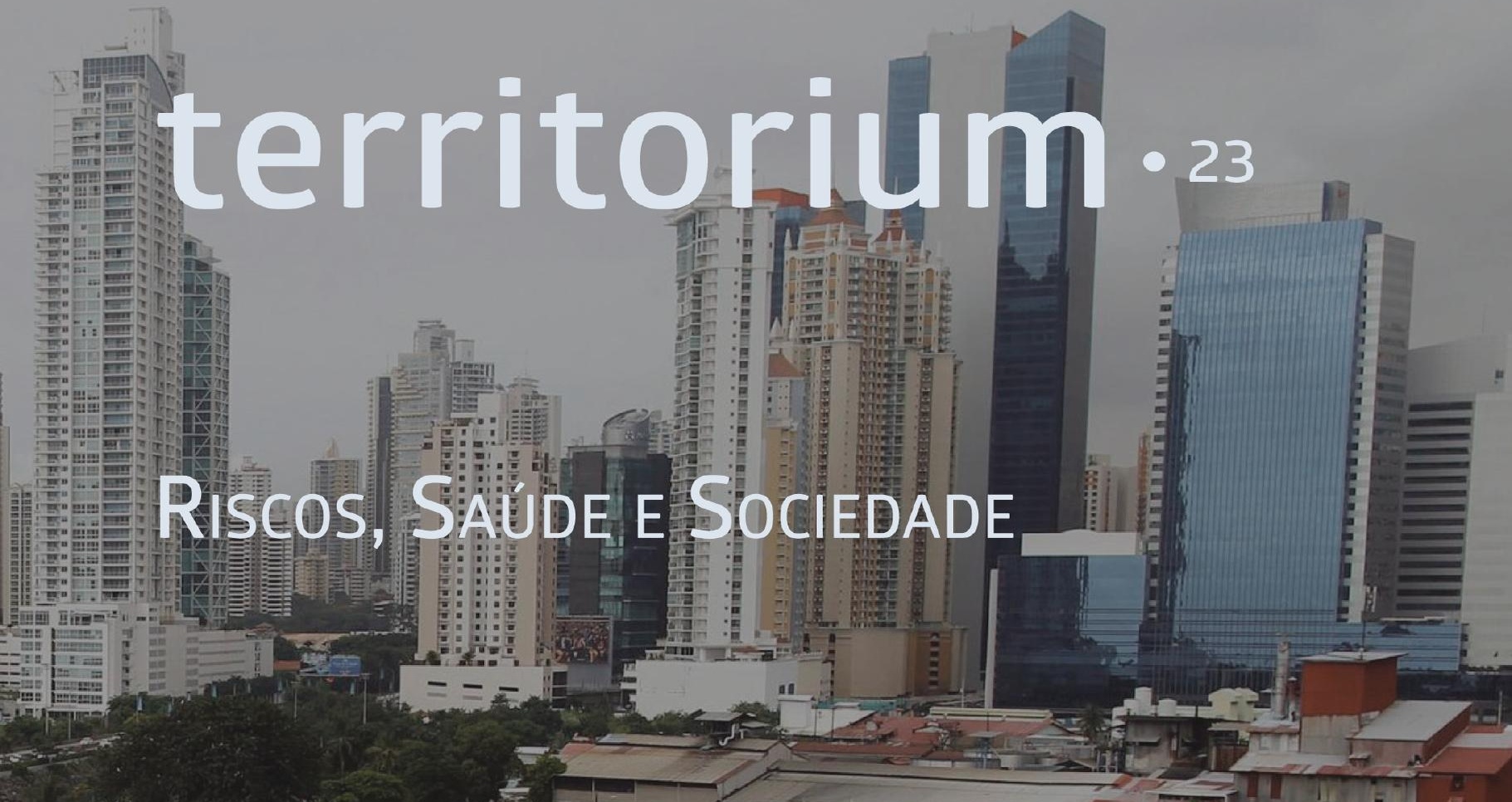

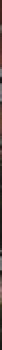

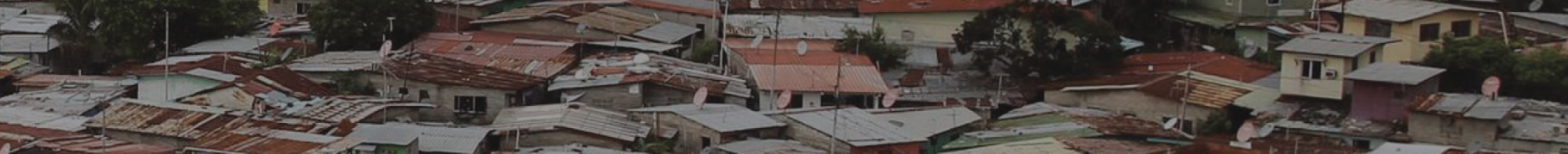

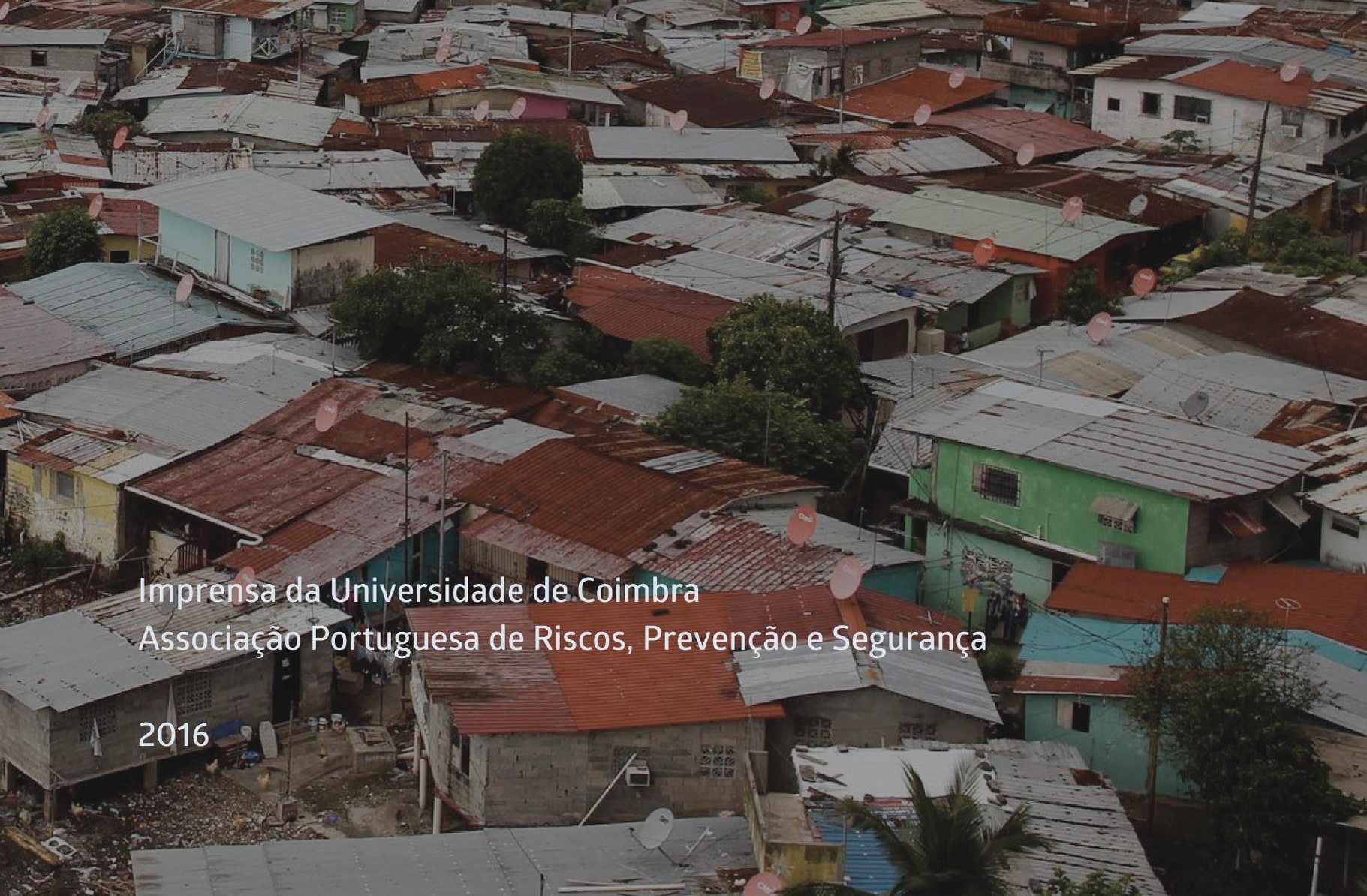


EFFECT OF THE CATRAIA FIRE ON THE HYDROLOGIC RESPONSE OF THE SÉQUA BASIN

Soraia Almeida

Mestre em Engenharia Civil, Universidade do Algarve soraiabeatrizalmeida@gmail.com

Fernando Martins

CIEO, ISE, Universidade do Algarve

fmmartin@ualg.pt

Helena Fernandez

CIEO, ISE, Universidade do Algarve

hfernand@ualg.pt

Celestina Pedras

LEAF/ISA. FCT, Universidade do Algarve

cpedras@ualg.pt
Elisa Silva

ISE, Universidade do Algarve esilva@ualg.pt

Rui Costa

ISE, Universidade do Algarve rcosta@ualg.pt

Rui Lança

ISE, Universidade do Algarve rlanca@ualg.pt

\section{RESUMO}

O uso e a ocupação do solo, e os incêndios florestais influenciam a relação entre precipitação-escoamento superficial e, consequentemente, o regime de cheias num curso de água. Neste estudo utilizou-se o modelo Hydrologic Engineering Center - Hydrologic Modeling System para simular a resposta hidrológica da bacia hidrográfica do Rio Séqua, em cenário pré-incêndio e pós-incêndio de Catraia, Algarve, Portugal. Os resultados revelam que os caudais de ponta de cheia sofrem um incremento de $25 \%$ nas sub-bacias hidrográficas mais afetadas pelo incêndio.

Palavras-chave: Precipitação, infiltração, bacia hidrográfica, incêndio florestal, hidrograma de cheia.

\section{ABSTRACT}

The soil use and forest fires have effects on the potential infiltration and consequently on the down-flow floods. The Hydrologic Engineering Center - Hydrologic Modeling System was used for modeling the hydrologic response of the Séqua basin, on pre-fire and post-fire scenarios, for the Catraia forest fire, Algarve, Portugal. The results show that peak flows could increase by $25 \%$ on the sub-basins where the fire effects were more severe.

Keywords: Rainfall, infiltration, hydrographic basin, forest fires, floods.

\section{RESUMEN}

Efecto del incendio de Catraia en el comportamiento hidrológico de la cuenca del Séqua - El uso del suelo y los incendios forestales tienen efecto sobre la infiltración potencial del agua en el terreno y, por consecuencia, en las inundaciones río abajo. En este trabajo fue aplicado el modelo Hydrologic Engineering Center - Hydrologic Modeling System, para el modelado de la respuesta hidrológica de la cuenca de Séqua, en escenarios anterior y posterior al incendio de Catraia, Algarve, Portugal. Los resultados obtenidos revelan que los flujos de pico pueden aumentar en un $25 \%$ en las sub-cuencas más afectadas por el incendio.

Palabras clave: Lluvia, infiltración, cuenca hidrográfica, incendios forestales, inundaciones.

\section{RESUMÉ}

L'effet de l'incendie de Catraia dans la réponse hydrologique du bassin du fleuve Séqua - Les feux de forêt et l'utilisation du sol influencent la capacité d'infiltration des eaux de précipitation dans le sol et, par conséquent, les inondations associées à un cours d'eau. Dans cette étude, le modèle Hydrologic Engineering Center - Hydrologic Modeling System a été appliqué pour simuler la réponse hydrologique du bassin de la rivière Séqua, selon un scénario avant et après incendie, pour le cas de l'incendie de Catraia, Algarve, Portugal. Les résultats obtenus montrent que les débits de pointe souffrent une augmentation de $25 \%$ dans les sous-bassins les plus touchés par le feu.

Mots-clé: Précipitations, infiltration, bassin hydrographique, incendies de forêt, hydrogramme de crue.

* O texto deste artigo corresponde a uma comunicação apresentada no I Seminário da Rede Incêndios-Solo e I Simpósio Ibero-Afro-Americano de Riscos, tendo sido submetido em 24-11-2015, sujeito a revisão por pares a 24-03-2016 e aceite para publicação em 30-06-2016.

Este artigo é parte integrante da Revista Territorium, n. ${ }^{\circ} 23,2016,{ }^{\circ}$ RIscos, ISSN: 0872-8941. 
Introdução

Nas últimas décadas a frequência e a intensidade dos incêndios florestais tem aumentado, principalmente nos países do Sul da Europa, com grandes perdas humanas, ambientais e económicas (Shakesby, 2011).

A ocorrência de um incêndio depende de muitos fatores, nomeadamente, a localização geográfica, as características climáticas, a variabilidade interanual da precipitação e o tipo de uso do solo (Nunes et al., 2014). Um pouco por toda a bacia Mediterrânica, as cargas de material combustível nas florestas têm aumentado nas últimas décadas, devido à desertificação demográfica do interior e aos programas de florestação (Lourenço, 2006). De acordo com os cenários de alterações climáticas dados pelo Intergovernmental Panel on Climate Change (IPCC) são de esperar períodos de seca mais prolongados, temperaturas mais altas e ventos mais fortes (Bento-Gonçalves et al., 2011; Santos et al., 2002). A longo prazo verifica-se uma tendência para o aumento da ocorrência de incêndios florestais (BentoGonçalves et al., 2011).

É conhecido que após um incêndio florestal a taxa de infiltração potencial dos solos tende a diminuir, o que modifica o comportamento hidrológico da bacia hidrográfica (Moody et al., 2015). Dada a importância do incêndio de Catraia surge a necessidade de conhecer a taxa de infiltração potencial, por forma a melhor entender o comportamento hidrológico da bacia hidrográfica do rio Séqua. Este estudo visa, assim, quantificar as modificações que o incêndio florestal induz na resposta hidrológica da bacia hidrográfica em cenário de precipitação intensa.

Este estudo tem como objetivo simular a resposta hidrológica da bacia hidrográfica do Rio Séqua, em cenários pré e pós-incêndio de Catraia, Algarve, Portugal, por forma a ajudar stakeholders na tomada de decisão sobre as estratégias a adotar nestes cenários.

\section{Material e métodos}

O caso de estudo foi desenvolvido na bacia hidrográfica do rio Séqua $\left(37^{\circ} 6.7^{\prime} \mathrm{N}\right.$ a $37^{\circ} 14.7^{\prime} \mathrm{N}$ e $7^{\circ} 38.2^{\prime} \mathrm{O}$ a $7^{\circ} 57.2^{\prime}$ 0) com área de cerca de $222.2 \mathrm{~km}^{2}$. Esta bacia estendese de oeste para este desde de São Brás de Alportel até Tavira. 0 principal curso de água é o rio Séqua que resulta da confluência das ribeiras do Alportel e da Assêca, e desagua na Ria Formosa, na zona das Quatro Águas. Este curso de água adquire o nome de Rio Gilão a partir da secção em que passa a sofrer o efeito da maré e constitui a linha de água mais importante do sistema hidrográfico do sotavento algarvio. Na bacia hidrográfica do rio Séqua existem cinco sub-bacias (fig.1; TABELA I): Malhada do Judeu, Alportel1, Alportel2, Assêca e Séqua.

As classes taxonómicas do solo estão apresentadas na fig. 2. As sub-bacias localizadas na serra algarvia (Alportel 1, Alportel 2 e Malhada do Judeu) apresentam litossolos dos climas de regime xérico de xistos ou grauvaques (Ex). As sub-bacias no barrocal algarvio (Assêca e Séqua) são constituídas por solos mediterrâneos calcários vermelhos (Vcd), solos calcários pardos dos climas de regime xérico, normais de calcários não compactos $(\mathrm{Pc})$ e afloramentos rochosos de calcário $(\operatorname{Arc})$.

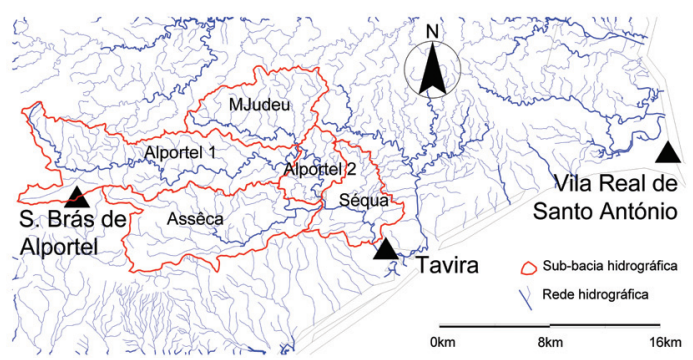

Fig. 1- Bacia hidrográfica do rio Séqua e respetiva rede hidrográfica.

Fig. 1 - Hydrographic basin from river Séqua and hydrographic network.

TABeLA I - Características das sub-bacias hidrográficas (IGeoE, 2012).

TABLE I-Characteristics of the hydrographic sub-basins (IGeoE, 2012).

\begin{tabular}{lrrrrr}
\hline \multicolumn{1}{c}{ Sub-bacias } & Alportel1 & Alportel2 & Assêca & M.Judeu & Séqua \\
\hline Área $\left(\mathrm{km}^{2}\right)$ & 75.89 & 16.27 & 62.55 & 40.00 & 27.52 \\
Perímetro $(\mathrm{km})$ & 3688.84 & 1128.27 & 1591.50 & 2920.38 & 714.12 \\
Fator de compacidade & 2.12 & 1.33 & 1.78 & 1.48 & 1.63 \\
Comprimento da linha de água principal $(\mathrm{km})$ & 39.09 & 9.54 & 22.09 & 13.17 & 7.78 \\
Declividade equivalente constante (\%) & 0.74 & 0.41 & 1.02 & 1.69 & 0.21 \\
Tempo de concentração $(\mathrm{h}){ }^{*}$ & 7.37 & 3.12 & 4.19 & 2.35 & 3.47 \\
\hline
\end{tabular}

* Calculado pelo método de Kirpich (Lencastre e Franco, 1992) 


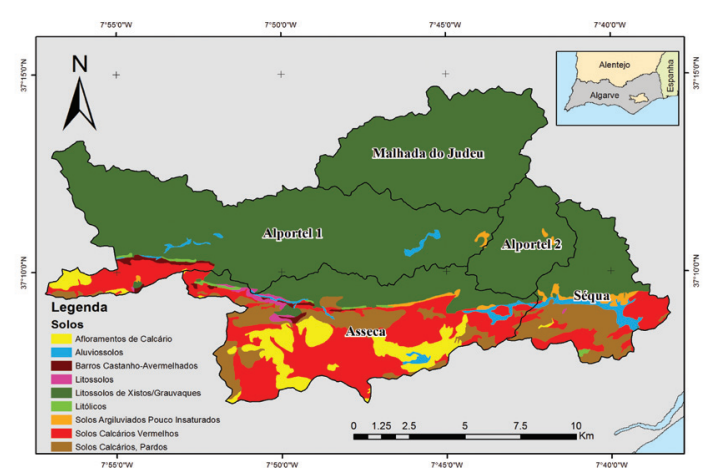

Fig. 2 - Classes taxonómicas do solo da bacia hidrográfica do Rio Séqua (Adaptado de SROA, 1973).

Fig. 2 - Taxonomic classes from the soils of the Séqua hydrographic basin (Adapt from SROA, 1973).

A fig. 3 representa o uso e ocupação do solo da bacia hidrográfica do rio Séqua. Os espaços naturais (vegetação arbustiva e mato baixo) e culturas permanentes (pomares e vinhas) são os mais representativos na área de estudo.

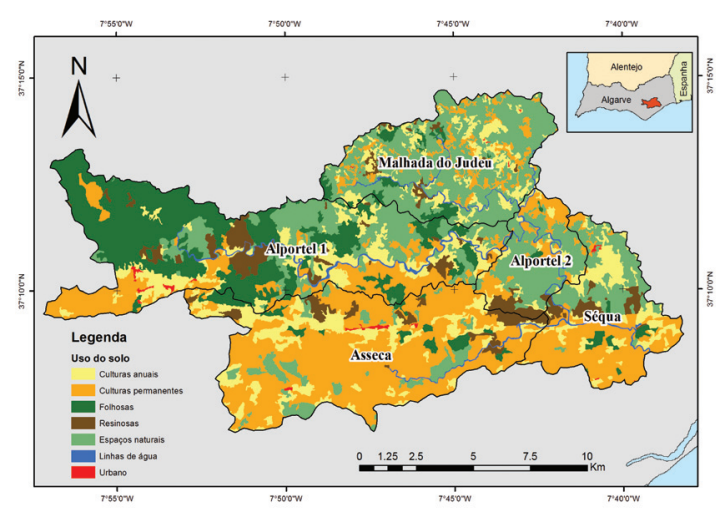

Fig. 3 - Classes de uso do solo da bacia hidrográfica do rio Séqua (Adaptado de COS'90, 1990)

Fig. 3 - Soil use classes on the Séqua hydrographic basin (Adapted from COS'90, 1990).

A fig. 4 apresenta a bacia hidrográfica do rio Séqua afetada pelo incêndio florestal de Catraia, ocorrido em 18 julho de 2012. Este incêndio foi considerado o sexto maior incêndio registado em Portugal nesse ano. A área ardida foi principalmente de sobreiro, pinheiro manso e matos (ICNF, 2012).

\section{Curva número}

A taxa de infiltração, $f$, representa a água que entra através da superfície do solo por unidade de tempo, sendo expressa em $\mathrm{mm} \mathrm{h}^{-1}$. A infiltração acumulada, $F$ (Eq.1), traduz a profundidade acumulada da água que é infiltrada, durante um determinado período de tempo, dado por (Chow et al., 1988):

$$
F(t)=\int_{0}^{t} f(t)
$$

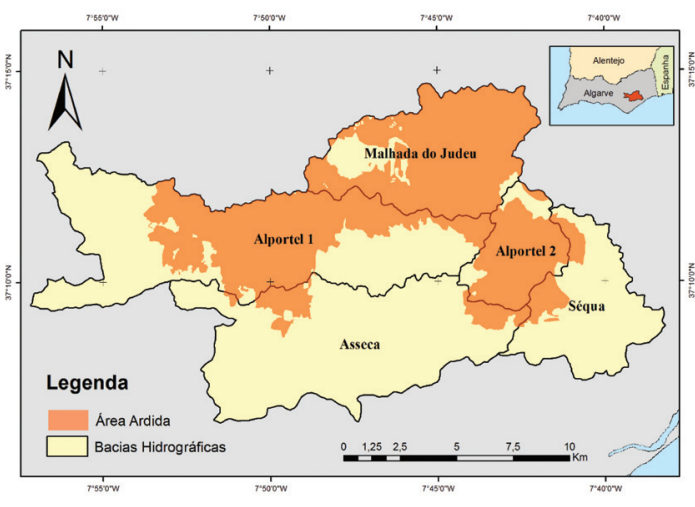

Fig. 4 - Localização da bacia hidrográfica do Rio Séqua e a respetiva área ardida no Incêndio de Catraia em 2012.

Fig. 4 - Location of the Séqua basin and area affected by the Catraia fire in 2012.

A taxa de infiltração é dada pela seguinte equação:

$$
f(t)=\frac{d F(t)}{d t}
$$

O método Soil Conservation Service, SCS (1972), permite calcular a parcela da precipitação, $P$, que contribui para o escoamento superficial $P_{e}$.

$$
P_{e}=\frac{\left(P-\frac{5080}{C N}+50.8\right)^{2}}{P+\frac{20320}{C N}-203.2}
$$

A Curva Número $(C N)$ que representa o escoamento, varia entre 0 e 100 . Assume valor 100 para superfícies completamente impermeáveis e valores menores que 100 para superfícies naturais. Segundo Chow et al. (1988) e Franco e Lencastre (1992) os números de escoamento são estabelecidos empiricamente em função da textura e do uso do solo. A CN de uma sub-bacia hidrográfica resulta da média dos $\mathrm{CNi}$ de cada polígono derivado da interseção das classes taxonómicas dos solos (Kopp et al., 1989) com as classes de uso e ocupação do solo (COS'90, 1990).

$\mathrm{Na}$ situação de pós-incendio as $C N$ (TABELA II) foram corrigidas com base na metodologia proposta por Higginson e Jarnecke (2007). A severidade do incêndio foi calculada com base no índice diference Normalized Burn Ratio (dNBR) aplicado às imagens LANDSAT_7, de préincêndio de 06-10-2011 com a pós-incêndio de 21-08-2012, 24-08-2013 e 27-08-2014. Este índice permitiu classificar a severidade do incêndio em 4 classes: recuperada (1), baixa (2), moderada (3) e alta (4) ao longo de 3 anos consecutivos, obtidos das seguintes equações: 


$$
\begin{gathered}
d N B R=N B R_{\text {pré-incêndio }}-N B R_{\text {prós-incêndio }} \\
N B R=\frac{B_{4}-B_{6}}{B_{4}+B_{6}}
\end{gathered}
$$

Sendo: B4 e B6 as bandas do infravermelho próximo e médio, respetivamente.

$$
\begin{gathered}
\text { TABELA II - Valores de } \mathrm{CN}_{\text {pré-incêndio }} \text { e } \mathrm{CN}_{\text {pós-incêndio }} \text {, Higginson e } \\
\text { Jarnecke (2007). }
\end{gathered}
$$

$T_{A B L E}$ II - Curve number, $\mathrm{CN}_{\text {pre-fire }}$ and $\mathrm{CN}_{\text {post-fire }}$, Higginson and Jarnecke (2007).

\begin{tabular}{ll}
\hline \multicolumn{1}{c}{ Severidade do Incêndio } & $\mathrm{CN}_{\text {pós-incêndio }}$ \\
\hline Alta & $\mathrm{CN}_{\text {pré-incêndio }}+15$ \\
Moderada & $\mathrm{CN}_{\text {pré-incêndio }}+10$ \\
Baixa & $\mathrm{CN}_{\text {pré-incêndio }}+5$ \\
\hline
\end{tabular}

\section{Biomassa}

Para estimar a biomassa pré-incêndio foram efetuadas medições no campo (junho 2015) do diâmetro do tronco e da altura do coberto vegetal predominante na área de estudo, sobreiros e arbustos, em sete zonas amostrais não ardidas, coordenadas com GPS. Em gabinete, localizaramse essas zonas na fotografia aérea e, sobrepondo com a imagem Landsat_7, foram contabilizados o número de sobreiros e arbustos existentes num pixel de $30 \mathrm{~m}$ (resolução da imagem Landsat_7).

A biomassa foi estimada através das seguintes equações (Pereira et al.,1995; Florete et al., 1988):

$$
\text { Biomassa Arbusto }=0.642 \cdot H^{0.0075} \cdot d^{2.4901} \cdot 166.67
$$

$$
\text { Biomassa Sobreiro }=-16.6845+0.65729 \cdot d^{2} \cdot H
$$

Sendo: $d$, o diâmetro do tronco, em $\mathrm{cm}$, e $\mathrm{H}$ a altura de copa, em cm.

Para estimar a biomassa para toda a área de estudo, foi calculado o índice de vegetação Normalized Difference Vegetation Index (NDVI) e aplicada uma regressão linear entre o NDVI e os valores de biomassa obtidos das Eq. 6 e 7. O cálculo do NDVI foi obtido das imagens LANDSAT_7 de 06-10-2011.

\section{Modelação hidrológica}

Dois hietogramas foram calculados de acordo com as curvas de possibilidade udométrica (TABELA III), para o período de retorno, $\operatorname{Tr}_{10}=10$ anos e para $\operatorname{Tr}_{100}=100$ anos, com a aplicação do método dos blocos alternados (Chow et al., 1988). As precipitações foram calculadas em intervalos de tempo Tc/5 (Tc é o período de retorno da maior bacia hidrográfica). As precipitações incrementais foram calculadas e rearranjadas de modo a que o valor mais elevado se localize no centro do hietograma, sendo os restantes valores dispostos por ordem decrescente, alternadamente, um à direita e outro à esquerda, do bloco central.

TABELA III - Curvas de possibilidade udométrica (DR. n. ${ }^{\circ} 23 / 95$, 23 de agosto).

$T_{A B L E}$ III - Intensity-duration-frequency curves (DR. n. ${ }^{\circ} 23 / 95$, 23 of August).

\begin{tabular}{cc}
\hline $\operatorname{Tr}=_{10 \text { anos }}$ & $\operatorname{Tr}=_{100 \text { anos }}$ \\
\hline$P=30.7 \cdot t^{0.451}$ & $P=45.7 \cdot t^{0.492}$ \\
\hline
\end{tabular}

A bacia hidrográfica do rio Séqua foi modelada, tendo por base cinco sub-bacias (fig. 5) e dois troços de rio (TABELA IV), com recurso ao software Hydrologic Engineering Center - Hydrologic Modeling System (HEC-HMS, 2015). Foram aplicados os métodos: Curva Número corrigida para atender ao efeito dos incêndios florestais no cálculo da precipitação efetiva; método do hidrograma unitário do SCS para a transformação da precipitação em escoamento superficial; e método da onda cinemática para o cálculo do escoamento em regime variável nos troços de rio considerados.

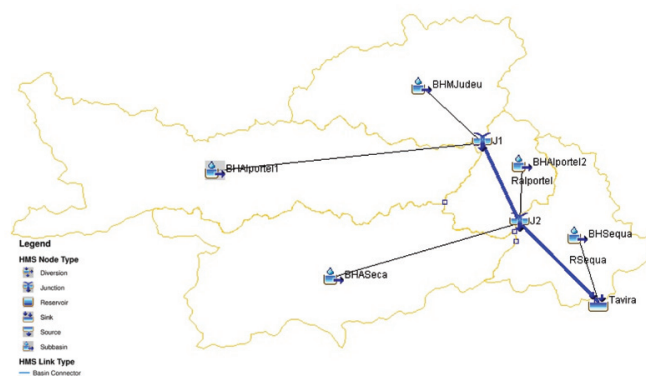

Fig. 5 - Esquema do modelo Hidrológico da bacia hidrográfica do Séqua no HEC-HMS.

Fig. 5 - Scheme of the Hydrologic model of Séqua basin on the HEC-HMS.

\section{Resultados e discussão}

A fig. 6 traduz os valores de $C N_{\text {pré-incêndio }}$ atribuídos a cada uma das classes de infiltração. Verifica-se que os maiores valores de escoamento se localizam na sub-bacia de Alportel 2, caracterizada por solos de xisto e grauvaques e uma cobertura de vegetação arbustiva e mato baixo. Os menores valores localizam-se na sub-bacia da Assêca nas zonas de afloramentos calcários. 
TABela IV - Características dos troços do rio Séqua.

$T_{A B L E} I V$ - Characteristics of the Séqua river sections.

\begin{tabular}{ccccccc}
\hline Troços de rio & $\begin{array}{c}\text { Comprimento } \\
(\mathrm{m})\end{array}$ & $\begin{array}{c}\text { Declive } \\
(\%)\end{array}$ & $\begin{array}{c}\text { Coeficiente de } \\
\text { Manning Strickler } \\
\left(\mathbf{m}^{-1 / 3} \mathbf{s}\right)\end{array}$ & $\begin{array}{c}\text { Largura } \\
(\mathbf{m})\end{array}$ & $\begin{array}{c}\text { Inclinação } \\
\text { da margem }\end{array}$ & Secção \\
\hline RAlportel & 8475 & 0.4 & 0.035 & 25 & $1: 1$ & Trapezoidal \\
RSéqua & 5885 & 0.2 & 0.040 & 250 & \\
\hline
\end{tabular}

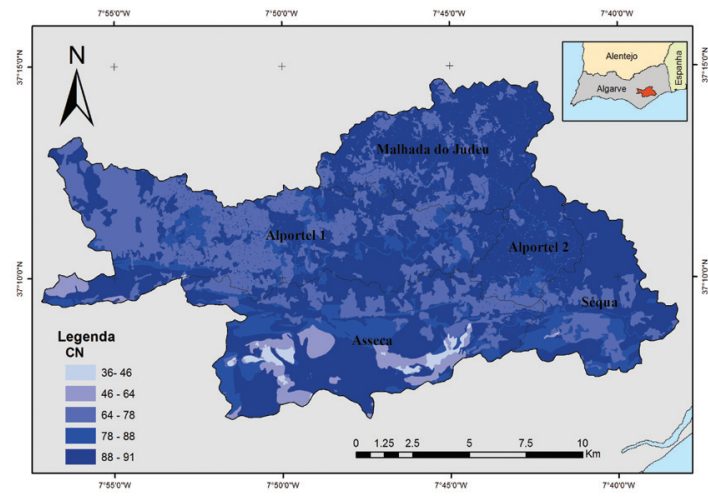

Fig. 6 - Valores de $C N_{\text {pré-incêndio }}$ da bacia hidrográfica do Rio Séqua.

Fig. 6 - Pre-fire curve number, $\mathrm{CN}_{\text {pre-fire }}$, on the Séqua hydrographic basin.

Na TABELA $V$ são apresentados os valores de biomassa obtidos para as sete zonas amostrais. A fig. 7 apresenta os valores de NDVI e a localização das sete zonas amostrais. Os maiores valores de NDVI encontram-se nas zonas de folhosas a noroeste da bacia.

A fig. 8 mostra a regressão linear entre o NDVI e a biomassa, para as sete zonas amostrais. O modelo apresenta um coeficiente de determinação $\left(R^{2}\right)$ elevado, de cerca de $84 \%$, o que mostra que a biomassa consegue ser explicada pelo NDVI.

TABELA V -Biomassa de sobreiros e de arbustos num pixel de $30 \mathrm{~m} \times 30 \mathrm{~m}$.

TABLE V - Biomass of corks and bushes on a pixel with $30 \mathrm{~m} \times 30 \mathrm{~m}$.

\begin{tabular}{lcrrr}
\hline Conjunto & $\begin{array}{c}\text { Biomassa } \\
\text { Sobreiro } \\
(\mathbf{g})\end{array}$ & $\begin{array}{c}\text { Biomassa } \\
\text { Arbusto } \\
(\mathbf{g})\end{array}$ & $\begin{array}{c}\text { Biomassa } \\
\text { Sobreiro } \\
\text { total } \mathbf{( k g )}\end{array}$ & $\begin{array}{c}\text { Biomassa } \\
\text { Arbustos } \\
\text { total }(\mathbf{k g})\end{array}$ \\
\hline 1 & 312919.08 & 0.06 & 2503 & 225 \\
2 & 622042.57 & 0.02 & 127 & 0 \\
3 & 719847.32 & 0.10 & 2879 & 0 \\
4 & 527064.17 & 0.02 & 5798 & 250 \\
5 & 505307.87 & 0.02 & 5558 & 1389 \\
6 & 335398.40 & 0.02 & 335 & 830 \\
7 & 328628.32 & 0.02 & 986 & 1667 \\
\hline
\end{tabular}

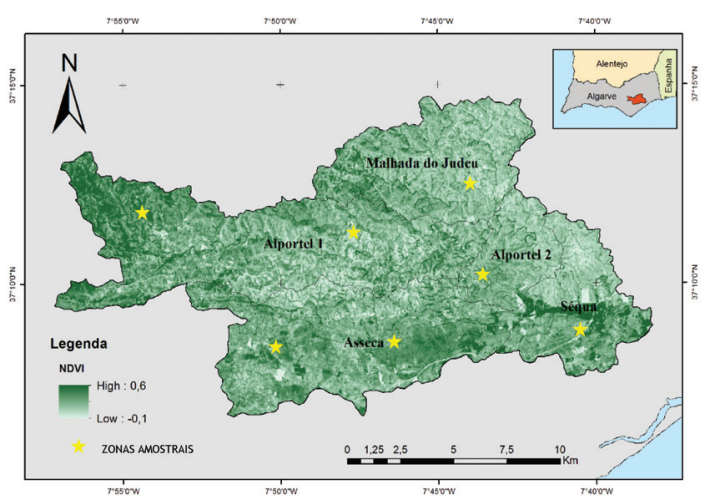

Fig. 7 - Índice NDVI, da bacia hidrográfica do Rio Séqua.

Fig. 7 - Index NDVI on the Séqua hydrographic basin.

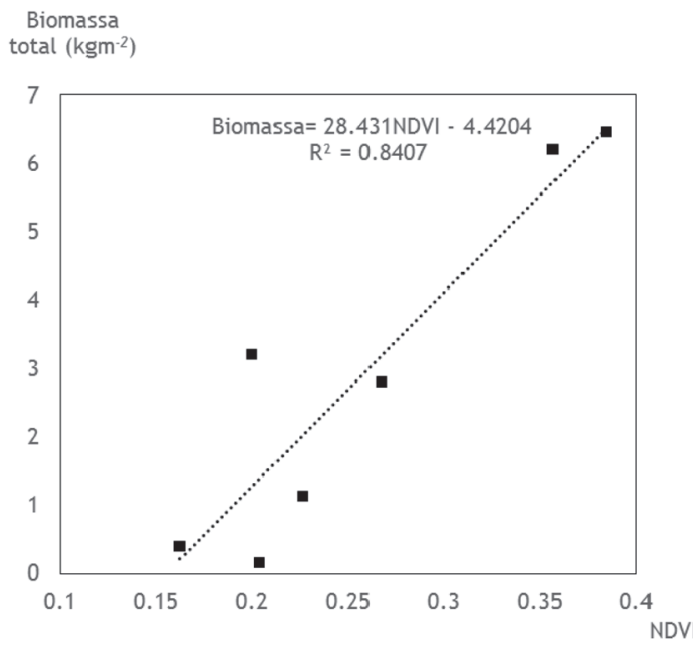

Fig. 8 - Relação entre o NDVI e Biomassa total.

Fig. 8 - Relation between NDVI and total biomass.

A fig. 9 cartografa a biomassa total, para as cinco subbacias hidrográficas, atendendo ao modelo de regressão anterior. Os maiores valores de biomassa correspondem aos maiores valores de NDVI.

As figuras 10, 11 e 12 apresentam INBR obtidos para os anos 2012, 2013 e 2014, respetivamente. A TABELA VI mostra a evolução das áreas para as diferentes classes de severidade: recuperada (1), baixa (2), média (3) e alta (4), ao longo dos 3 anos consecutivos. Verifica-se que a maior área ardida corresponde à 
sub-bacia MJudeu (83\% da área total) e a menor a da sub-bacia da Assêca ( $8 \%$ da área total). Em termos de recuperação do coberto vegetal constata-se uma evolução rápida, pois a severidade classificada de

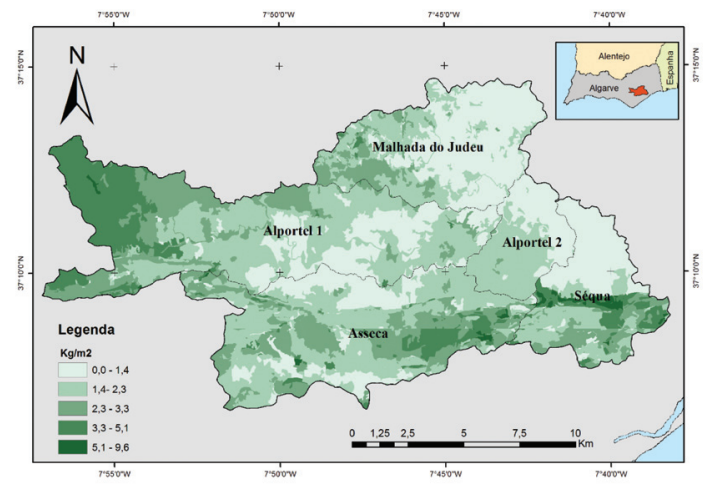

Fig. 9 - Biomassa acima do solo na bacia hidrográfica do Rio Séqua.

Fig. 9 - Above ground biomass on the Séqua hydrographic basin.

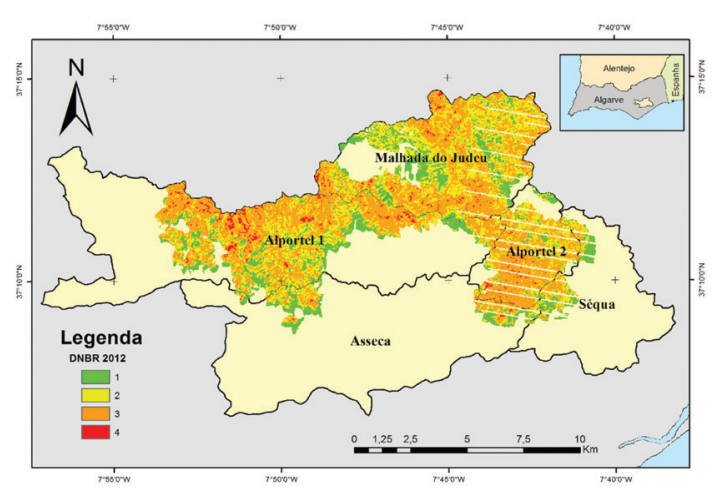

Fig. 10 - Mapa do índice diference Normalized Burn Ratio (dNBR) obtido em 2012.

Fig. 10 - Map of the index difference Normalized Burn Ratio (dNBR) obtained in 2012.

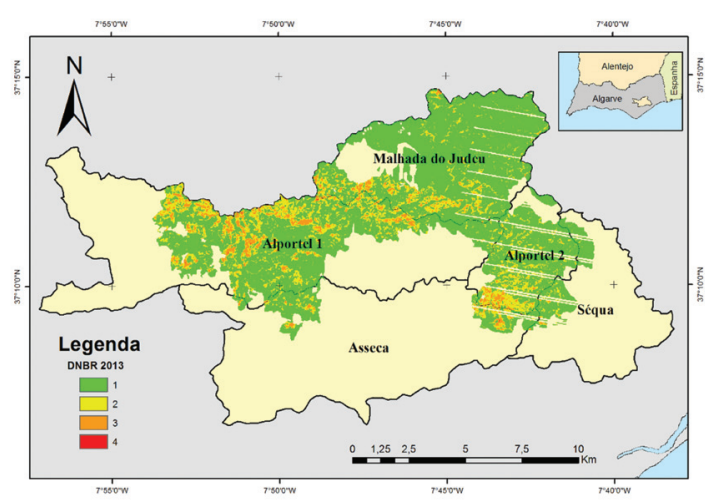

Fig. 11 - Mapa do índice diference Normalized Burn Ratio (dNBR) obtido em 2013.

Fig. 11 - Map of the index difference Normalized Burn Ratio (dNBR) obtained in 2013. média em 2012 altera-se para baixa e recuperada em 2013. No ano 2014 a evolução do coberto vegetal estabiliza e a classe de severidade, alta atribuída em 2012 e 2013, desaparece.

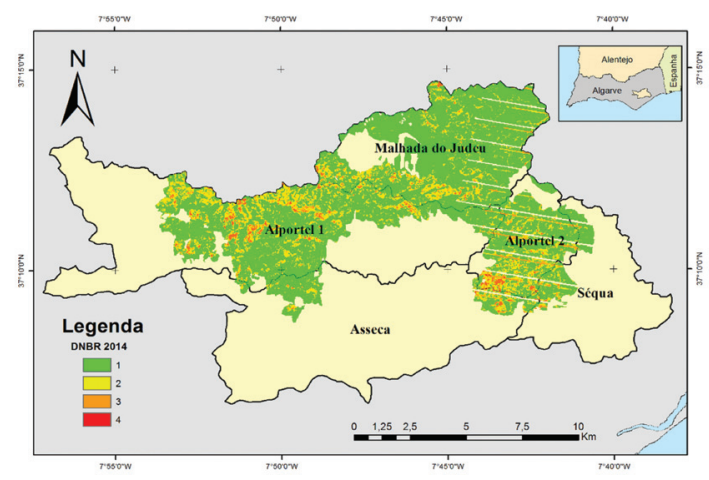

Fig. 12 - Mapa do índice diference Normalized Burn Ratio (dNBR) obtido em 2014.

Fig. 12 - Map of the index difference Normalized Burn Ratio (dNBR) obtained in 2014.

TABELA VI - Severidade da área ardida no incêndio de Catraia e julho de 2012.

$T_{A B L E}$ VI - Recovery of the burned area on the Catraia fire in 2012 July.

\begin{tabular}{|c|c|c|c|c|c|c|}
\hline DNBR & Ano & Alportel1 & Alportel2 & Assêca & MJudeu & Séqua \\
\hline & & \multicolumn{5}{|c|}{ Área ardida km² } \\
\hline & & 34.18 & 9.94 & 5.12 & 33.25 & 2.66 \\
\hline & & $(45 \%)$ & $(61 \%)$ & $(8 \%)$ & $(83 \%)$ & $(10 \%)$ \\
\hline 1 & & 4.97 & 0.63 & 1.86 & 4.48 & 0.85 \\
\hline 2 & & 10.65 & 2.76 & 1.70 & 13.83 & 0.99 \\
\hline & 2012 & & & & & \\
\hline 3 & & 17.41 & 6.40 & 1.40 & 14.58 & 0.74 \\
\hline 4 & & 1.16 & 0.19 & 0.058 & 0.46 & 0.00 \\
\hline 1 & & 22.94 & 6.99 & 3.76 & 28.31 & 2.22 \\
\hline 2 & & 8.64 & 2.59 & 0.96 & 4.25 & 0.25 \\
\hline & 2013 & & & & & \\
\hline 3 & & 2.65 & 0.39 & 0.29 & 0.79 & 0.02 \\
\hline 4 & & 0.006 & - & 0.001 & - & - \\
\hline 1 & & 23.90 & 6.70 & 3.82 & 27.79 & 2.05 \\
\hline 2 & & 9.33 & 2.97 & 1.05 & 5.25 & 0.40 \\
\hline & 2014 & & & & & \\
\hline 3 & & 1.03 & 0.31 & 0.15 & 0.31 & 0.04 \\
\hline 4 & & - & - & - & & \\
\hline
\end{tabular}


Os hietogramas obtidos para $T r_{10}$ e $T r_{100}$ são apresentados na fig. 13, onde se observa que a precipitação acumulada no evento pluviométrico para $T r_{100}$ é aproximadamente o dobro da obtida para $\operatorname{Tr}_{10}$.

$\mathrm{Na}$ modelação hidrológica foram considerados quatro cenários, o cenário pré-incêndio e os cenários pósincêndio de Catraia em 2012, 2013 e 2014. Para todos os cenários foram consideradas as precipitações associadas aos períodos de retorno de 10 e 100 anos, dando origem a 8 séries de resultados.

Os resultados (fig. 14) mostram que após o incêndio (ano 2012) há um incremento do caudal de ponta de cheia para $\operatorname{Tr}_{100}$ de $14 \%$ e para $\operatorname{Tr}_{10}$ de $25 \%$ face ao cenário pré-incêndio. Em 2013 esta diferença reduzse para 6\% e 10\%, para $\operatorname{Tr}_{100}$ e $T r_{10}$, respetivamente. As sub-bacias hidrográficas Alportel2, MJudeu e Alportel1, mais atingidas pelo incêndio, tiveram uma taxa de incremento do caudal de ponta de cheia para $\operatorname{Tr}_{100}$ de $15 \%, 15 \%$ e 20\% em 2012, 6\%, 6\% e 8\% em 2013, respetivamente. Em 2014 os valores permanecem praticamente constantes face ao ano anterior. Para $\operatorname{Tr}_{10}$, nas mesma sub-bacias, o aumento do caudal de ponta de cheia face ao cenário pré-incêndio em 2012 foram de 28\%, 28\% e 33\%, respetivamente. Em 2013, para $\mathrm{Tr}_{10}$, os incrementos de caudal esperado nestas sub-bacias hidrográficas foram de 10\%, 10\% e 14\% respetivamente. Em 2014, os valores permanecem praticamente constantes face ao ano anterior.

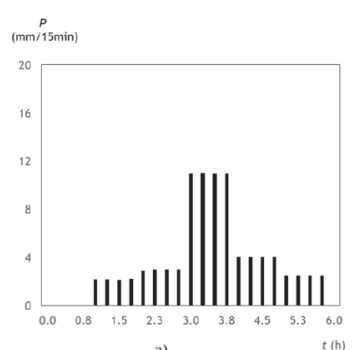

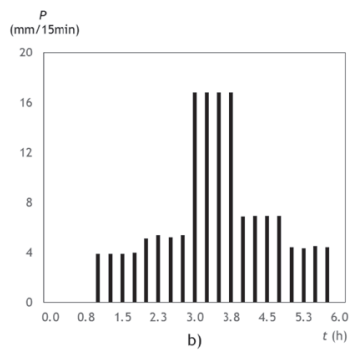

Fig. 13 - Hietogramas para: a) $\operatorname{Tr}_{10}$ e b) $T r_{100}$.

Fig. 13 - Hyetographs for: a) $\operatorname{Tr}_{10}$ and b) $\operatorname{Tr}_{100}$.

Após 2013, as sub-bacias hidrográficas mais afetadas pelo incêndio, apresentaram uma taxa de recuperação hidrológica elevada.

As sub-bacias hidrográficas Assêca e Séqua praticamente não foram afetadas pelo incêndio de Catraia, pelo que os caudais permaneceram quase constantes nos cenários estudados, contribuindo para que o efeito do incêndio de Catraia nos hidrogramas de cheia na cidade de Tavira tenha sido atenuado.

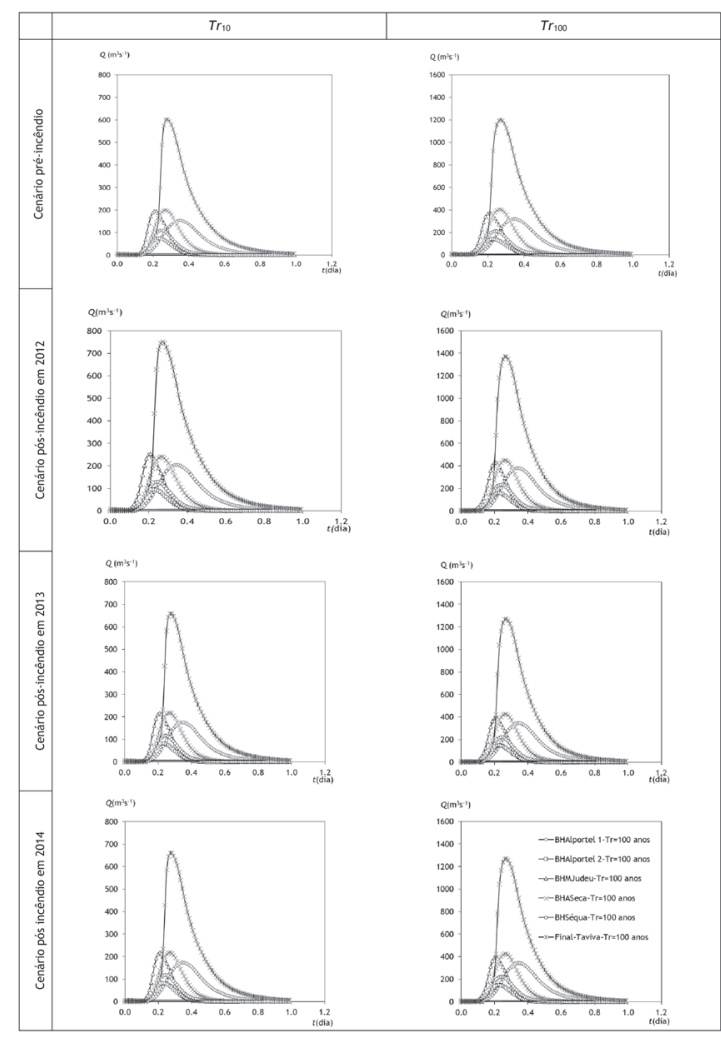

Fig. 14 - Hidrogramas de cheia para $T r_{10}$ e $T r_{100}$ nos cenários préincêndio e pós-incêndio.

Fig. 14 - Flood hyetographs for $\operatorname{Tr}_{10}$ and $\operatorname{Tr}_{100}$ on pre-fire and post fire scenarios.

\section{Conclusão}

Este estudo visou a simulação hidrológica da bacia hidrográfica do rio Séqua, em cenário pré e pós-incêndio de Catraia ocorrido em 18 julho de 2012. A monitorização do coberto vegetal após o incêndio de Catraia baseou-se na aplicação do índice diference Normalized Burn Ratio em imagens LANDSAT_ 7.

Verificou-se que, a recuperação do coberto vegetal foi mais rápida no primeiro ano após-incêndio, tendendo a estabilizar nos anos seguintes. No ano de 2014, a classe de 'severidade alta' deixou de existir.

As sub-bacias hidrográficas mais atingidas pelo incêndio foram Alportel2, MJudeu e Alportel1. As sub-bacias hidrográficas Assêca e Séqua praticamente não foram afetadas pelo incêndio, o que contribuiu para que o efeito do incêndio de Catraia no incremento do caudal de ponta de cheia em Tavira fosse minimizado.

Após o incêndio (ano 2012) na bacia do rio Séqua há um incremento do caudal de ponta de cheia para $\operatorname{Tr}_{100}$ de 14 \% e para $\operatorname{Tr}_{10}$ de $25 \%$ face ao cenário pré-incêndio, sendo que nas sub-bacias mais afetadas estes valores poderão ser mais elevados. 
Com vista a melhorar os resultados obtidos há necessidade de dar continuidade à monitorização da recuperação da bacia hidrográfica, e à análise entre hidrogramas calculados e as observações em campo.

\section{Referências bibliográficas}

Bento-Gonçalves, A., Vieira, A., Ferreira-Leite, F., Martins, J., Silva, D., \& Soares, V. (2011). Adaptaclima: Adaptação aos efeitos derivados das alterações climáticas. As Mudancas Climáticas e os Incêndios Florestais no Ave. Guimarães: AMAVE, 100.

Chow, V., Maidment, D., Mays, L. (1988). Applied Hydrology. McGraw-Hill, Singapore.

DGT-DIRECÃO GERAL DO TERRITÓRIO, COS'90 (1990). Carta de Uso e ocupação do Solo de Portugal Continental para 1990. Lisboa

Decreto regulamentar $n^{\circ} 23 / 95$ de 23 de agosto, Diário da República n. ${ }^{\circ}$ 194/1995, Série I-B de 1995-08-23.

HEC-HMS 4.1 (2015), Hydrologic Modeling System (HEC-HMS), Department of The Army Corps of Engineers. Institute for Water Resources. Hydrologic Engineering Center. 609 Second Street. Davis, CA 95616-4687. US.

ICNF - INSTITUTO DA CONSERVAÇÃO DA NATUREZA E DAS FLORESTAS (2012). Relatório da área ardida do Incêndio de Catraia. Relatório Técnico. http: // www.icnf.pt/portal/florestas/dfci/relat/raa.

IGEOE - INSTITUTO GEOGRÁFICO DO EXÉRCITO (2012). Carta militar de Portugal à escala de 1:25000. Instituto Geográfico do Exército, Lisboa. f. 589-590-591-598-599-600-607-608.

INTERGOVERNMENTAL PANEL ON CLIMATE CHANGE (IPCC), http: / / www.ipcc.ch / organization / organization.shtml, consultado 30/nov/2015.

Floret, C., Romane, F., Galan, M., Grandjanny, M. Floc'H, E., Maistre, M., Perret, P. (1988). Quelques remarques sur les taillis de chênes verts. Répartition, histoire, biomasse. Forêt méditerranéenne, t. X, $n^{\circ} 1$, juillet, p. 131-135.

Higginson, B., Jarnecke, J. (2007). Salt Creek BAER-2007 Burned Area Emergency Response. Provo, UT: Uinta National Forest; Hydrology Specialist Report. 11 p.
Lencastre, A., Franco, F.M. (1992). Lições de Hidrologia. Universidade Nova de Lisboa. Faculdade de Ciências e Tecnologia, Lisboa. 451 p.

Lourenço, L. (2006). Paisagens de Socalcos e riscos Naturais em Vales do Rio Alva. Núcleo de Investigação. Cientifica de Incêndios Florestais. Faculdade de Letras da Universidade de Coimbra.ISBN:9728330-200. http://www.uc.pt/fluc/nicif / Publicacoes/Colectaneas_Cindinicas/ Coletanea_Cindinica_VI.

Kopp, E., Sobral, M., Soares, T., Woerner, M. (1989). Os solos do Algarve e as suas Características. Ministério da Agricultura, Pescas e Alimentação - DGHEA. Direção Regional de Agricultura do Algarve, DRAA. Sociedade Alemã de Cooperação Técnica. Faro, Portugal.

Moody, J. A., Ebel, B. A., Nyman, P., Martin, D. A., Stoof, C., \& McKinley, R. (2015). Relations between soil hydraulic properties and burn severity. International Journal of Wildland Fire.

Nunes, A., Lourenço, L., Fernandes, S., \& Meira Castro, A. C. (2014). Principais causas dos incêndios florestais em Portugal: variação especial no período 2001/12. Territorium, 21, p. 135-146. http:// www.uc.pt/fluc/nicif/riscos/Documentacao/ Territorium/T21_artg/T21_artg11.pdf.

Pereira, J., Oliveira, T., Paul, J. (1995). Satellitebased estimation of mediterranean shrubland structural parameters. EARSel Advances in Remote Sensing Vol.4, No.3 - XII, Lisboa.

Santos, F., Forbes, K., Moita, R. (ed.) (2002) - Climate change in Portugal. Scenarios, Impacts and Adpatation Measures - SIAM Project, Gradiva, Lisboa, 454 p.

Shakesby, R. A. (2011). Post-wildfire soil erosion in the Mediterranean: review and future research directions. Earth-Science Reviews, 105(3), p. 71-100.

SROA - SERVICCO DE RECONHECIMENTO E DE ORDENAMENTO AGRÁRIO (1973). Carta de solos de Portugal. Classificação e caraterização dos solos em Portugal. II Volume. Dados analíticos das unidades pedológicas, $6^{a}$ ed.. Secretaria de Estado da Agricultura, Ministério da Economia. Lisboa. 

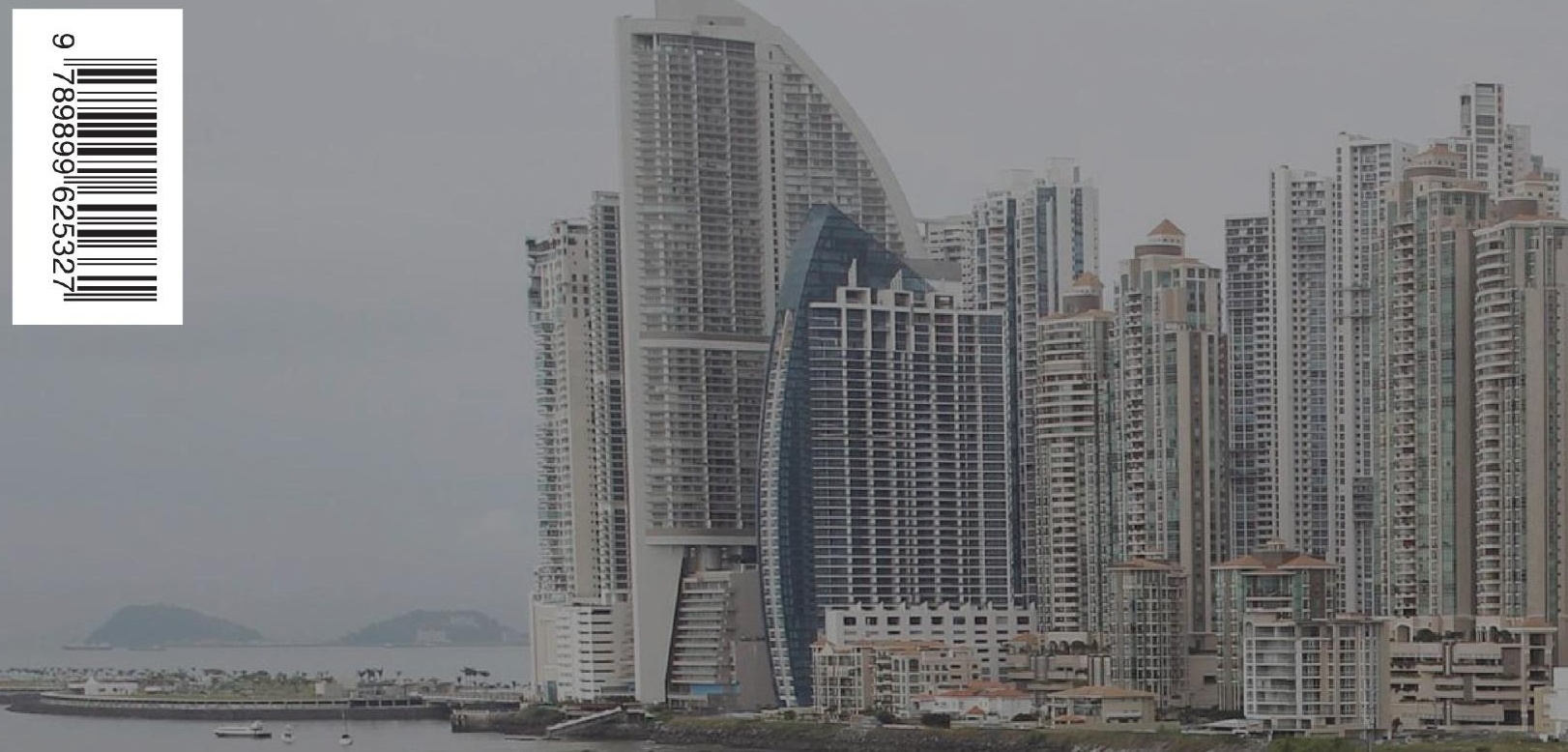

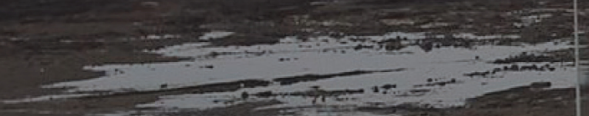

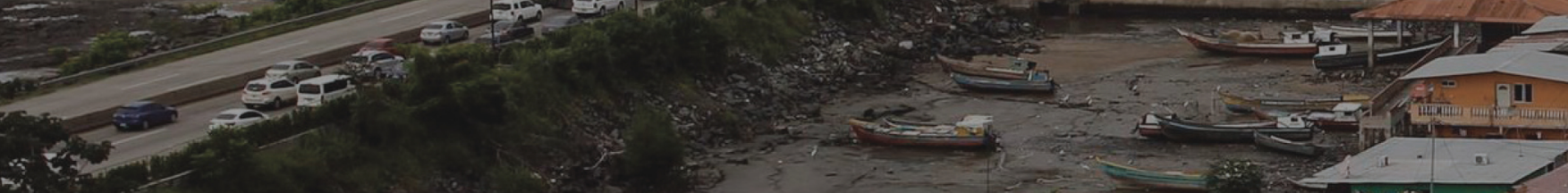

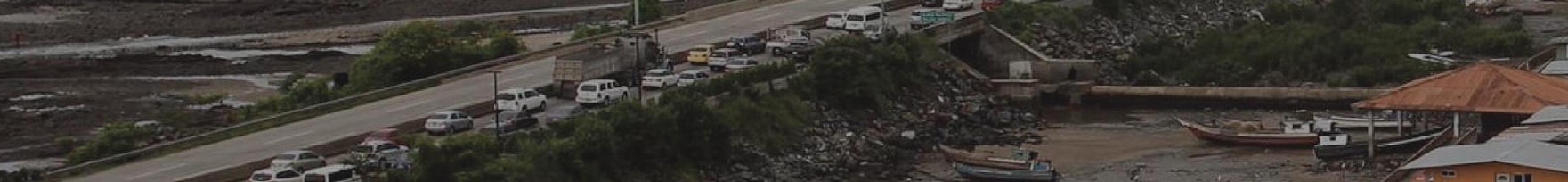
inse- $n=$ Riscos I I I

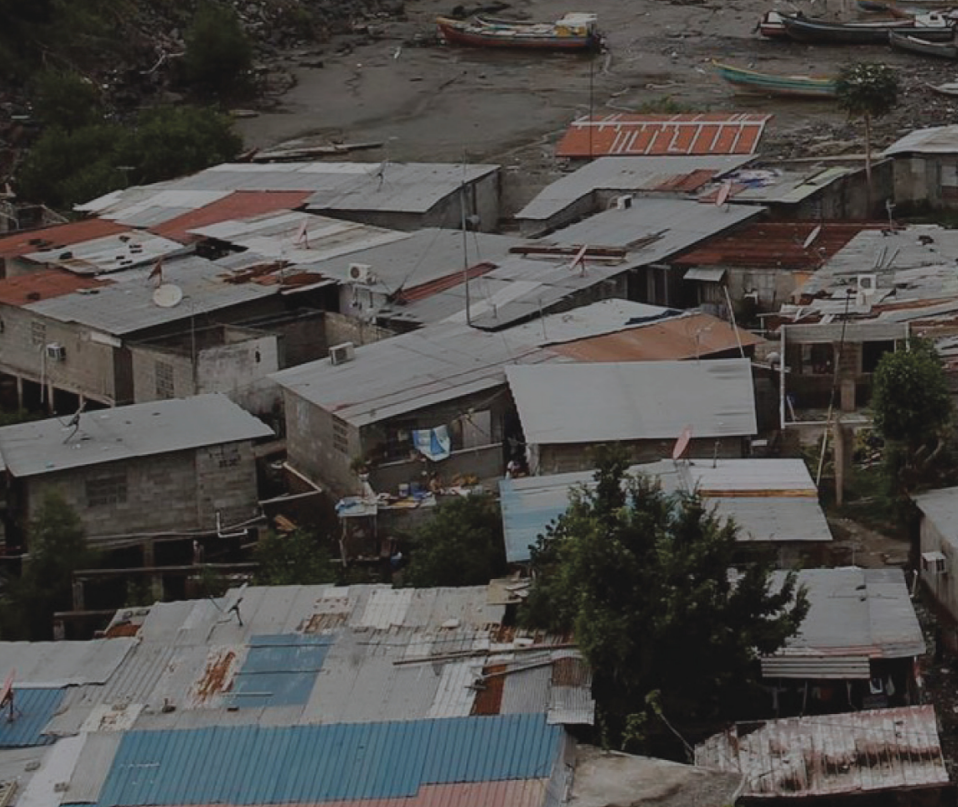

